\title{
Numerical Modelling of Interior RC Beam- Column Joints for Non-Engineered Buildings Strengthened Using Steel Plates
}

\author{
Yulita Rahmi ${ }^{1, *}$, Ashar Saputra ${ }^{2}$, and Suprapto Siswosukarto ${ }^{2}$ \\ ${ }^{1}$ Student, Department of Civil and Environmental Engineering, Universitas Gadjah Mada, \\ Yogyakarta, Indonesia \\ ${ }^{2}$ Department of Civil and Environmental Engineering, Universitas Gadjah Mada, Yogyakarta, \\ Indonesia
}

\begin{abstract}
Data examination regarding historical earthquakes in Indonesia has revealed that damages occurred mostly in non-engineered buildings. Many non-engineered buildings have serious design and construction deficiencies in using concrete of inadequate quality and have poor steel reinforcement detailing especially in their beam-column joints. These joints require an effective strengthening technique which is simple to install. This paper presents steel plates to reinforce concrete beam-column joints through numerical studies. The finite element model was developed using ABAQUS. The FEM results were validated by comparisons with previous experimental tests. For this purpose, two RC beam-column joints were analyzed, including original standard beam columns and non-standard steel detailing strengthened with steel plates. The comparison of the results from numerical model indicated that steel plates could increase lateral strength, ductility, energy dissipation and increase the shear strength of the joints.
\end{abstract}

\section{Introduction}

An earthquake in Indonesia on a few years ago caused many non-engineered buildings suffered slight or heavy structural damage. Generally, the damage in non-engineered buildings occur in the beam-column connections due to the connection details that are not resistant to the earthquake and low quality of concrete [1]. An effective strengthening technique to non-engineered buildings is simple to be implemented, not require a special skill, low cost, and have a good result. This study developed a numerical analysis of the research that had been conducted by experiment [2]. Several of research have been studied for upgrading beam-column joint.

\footnotetext{
${ }^{*}$ Corresponding author: yulita.civil@gmail.com
} 
Enveloped steel plates was used for strengthening RC frame joint. The steel plate was welded to the joint. This research showed that the stiffness, bearing capacity and integrity of the steel-enveloped frame joint are significantly improved, if compared to the primary frame joint [3]. Haunch retrofit solution was studied for retrofitted joints through numerical. This method showed that there is no critical shear occured in RC frame joint, but the haunch retrofit cause an increase in shear [4]. Steel prop and crub were studied for retrofitted reinforced concrete beam-column joints with experimental. This retrofit was used for strengthening of undamaged joints, because the shear stress and number of cracks at the panel zone were reduced. The maximum peak and load were incease $73 \%$ [5].

Most of these studies have a good result for beam-column joint, which have a difference technique application. Some of the advantages of the use of steel plate are having a greather tensile strength and easier implementation. Beam-column joints modelled using software ABAQUS 6.11 with two specimens. Numerical approach is expected to provide validate results to the beam-column joint. Therefore, the author perform further analysis of the interior beam-column joint using with steel plates in non-engineered buildings with numerical modeling. The purposes this research are the steel strip plate can be the alternative stiffener which effectively strength, increase the shear strength, and easy in implementation of the beam column joint and comparing the test results experimental that had been studied previously with numerical modeling.

\section{Finite element modeling}

The numerical study was developed using software ABAQUS 6.11.1. Concrete is modeled as C3D8R element. The rebar material is modeled as truss element. Steel rebars are tensile element on reinforced concrete, which are modeled as T3D2 (Truss, two-dimensional, number of nodes).

Reinforcement elements with concrete is designed as a surface embedded in the bonding relationship. Steel plates material and bolts are modeled as elastic perfectly plastic. Modeling process on steel plates and bolts used C3D8R solid. Contact between the concrete with bolts is defined by tie.

\subsection{Specimen details}

The FE model analysed the behavior beam-column joint with two specimens. The specimens were used in this study are named as HBK-1NA (normal beam column) and HBK-3A (beamcolumn joints with non-standars reinforcing strenghtened with steel plate). The beams cross section were 150x150 mm and columns cross section were 150x150 mm. The longitudinal reinforcement for all spesimen was $\otimes 10$. The transverse reinforcement for all spesimen was Q8. The cross section of steel strip plate was $656.7 \mathrm{~mm}$ length and $50 \times 3 \mathrm{~mm}$ width in the two side of joints. Specimens details that were tested are shown in Figure 1 and Figure 2.

\subsection{Constitutive of model material}

Material characteristic values are calculated based on experimental results with numerical validation which had been tested by several studies. The calculation of material properties used are described as follows. 


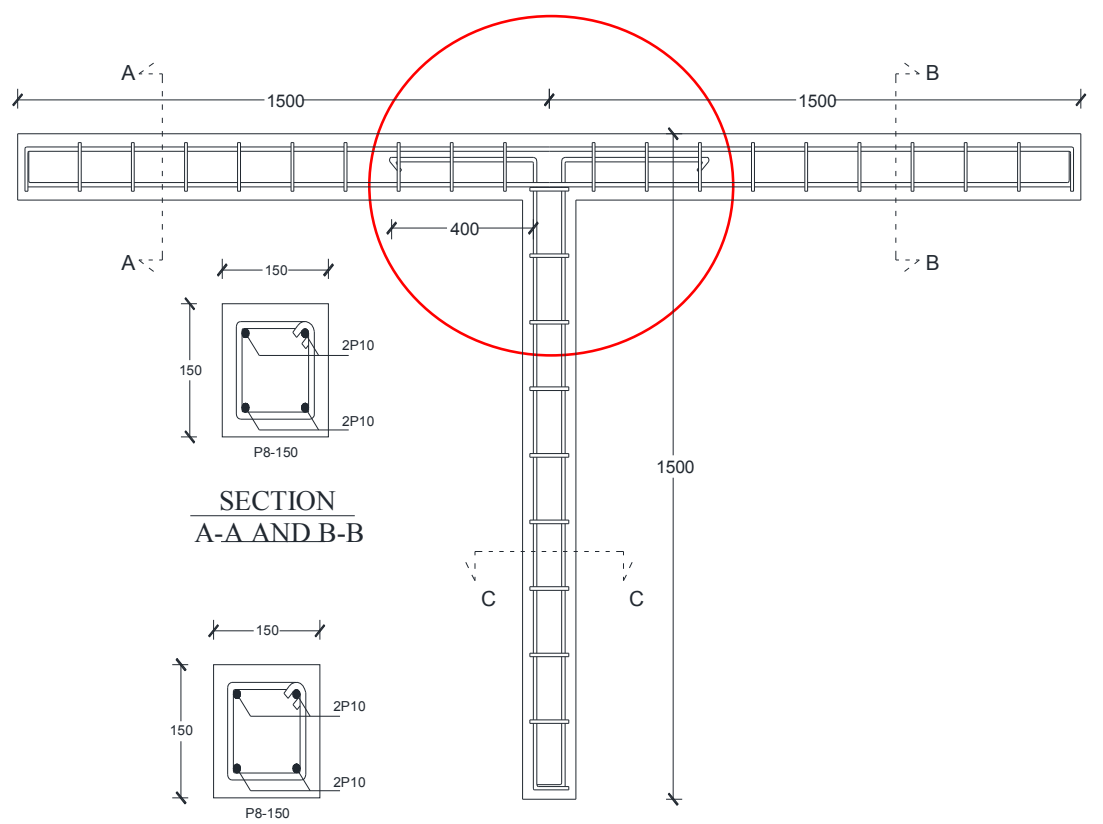

SECTION C-C

Fig. 1. Specimen HBK-1NA

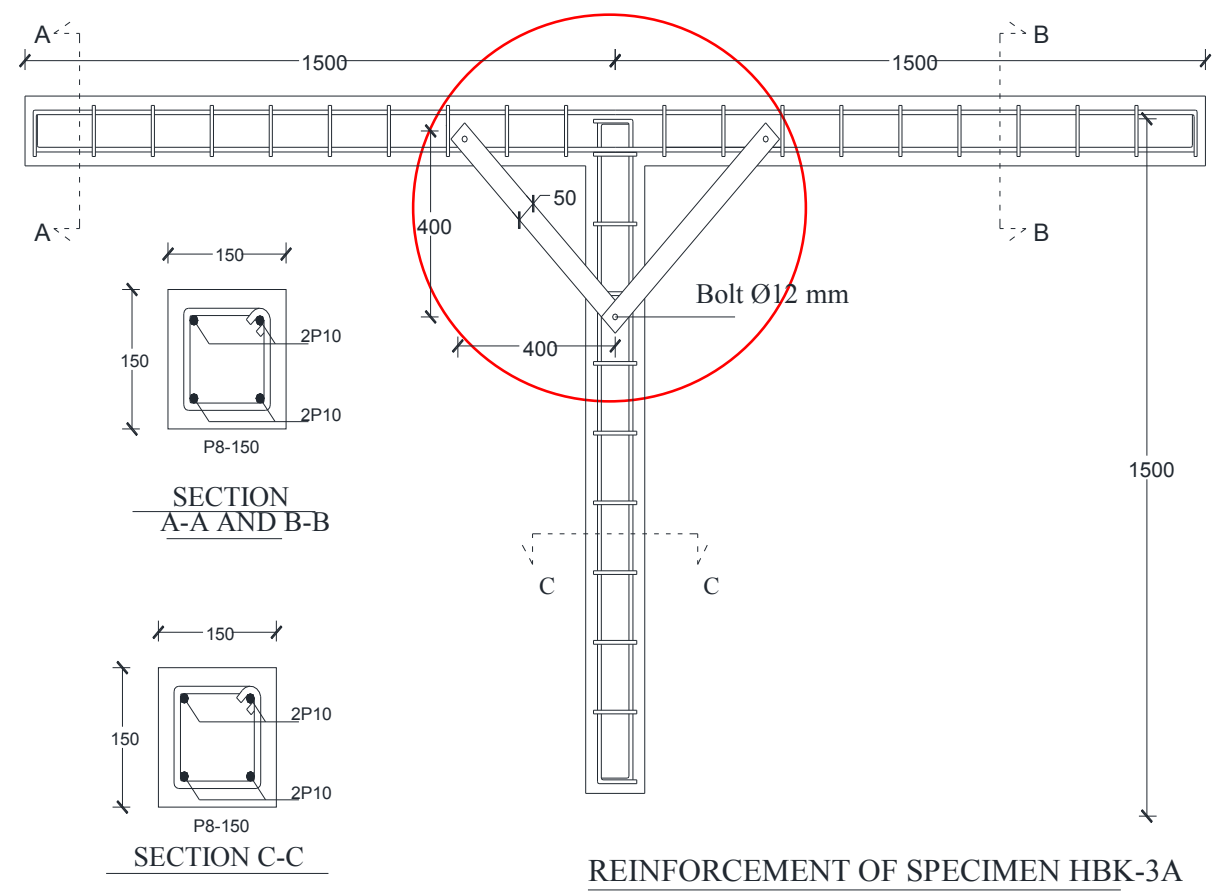

Fig. 2. Specimen HBK-3A 


\subsubsection{Concrete material}

Modelling of concrete material uses concrete damage plasticity. Concrete damage plasticity is general capability model for analysing concrete elements under monotonic and cyclic loading [6]. The model of CDP used in ABAQUS is a modification of hypotheses by Drucker-Prager. There are some parameters that are described in the plasticity of concrete namely, $\mathrm{K}_{\mathrm{c}}$ parameter, dilatation angle, eccentricity, the ratio of yielding concrete, and eccentricity [7]. The constitutive equation of concrete materials at the compressive conditions use the equation by Todeschini [8]. On tensile condition, material properties are calculated with an equation in CEB-FIP MC 1990 [9]. This equation is used to approximate calculation of the concrete compression stress and tensile stress to beam-column joints using steel plate. The stress-strain behavior of concrete in compression is assumed to be linearly elastic up to initial yield stress $\left(\sigma_{\mathrm{co}}\right)$. On the plastic condition, hardening stress that follows the softening until it reaches the ultimate stress $\left(\sigma_{\mathrm{cu}}\right)$. Concrete strength $\left(f_{\mathrm{cm}}\right)$ was used $15 \mathrm{MPa}$. The concrete stress-strain curve used for compression and tension for all model shown in Figure 3. The constitutive models of concrete materials calculated by the following equation:

$$
\sigma_{c}=\frac{2 f_{c}^{\prime}\left(\frac{\varepsilon_{c}}{\varepsilon_{c}^{\prime}}\right)}{1+\left(\frac{\varepsilon_{c}}{\varepsilon_{c}^{\prime}}\right)^{2}}
$$

with,

$$
\varepsilon_{c}^{\prime}=1,71 \frac{f_{c}^{\prime}}{E_{c}}
$$

where $\sigma_{\mathrm{c}}$ is compressive stress in concrete, $f_{c}^{\prime}$ is compressive strength of concrete, $\varepsilon_{\mathrm{c}}$ is strain in concrete, $\varepsilon_{c}^{\prime}$ is strain corresponding to $f_{c}^{\prime}$.

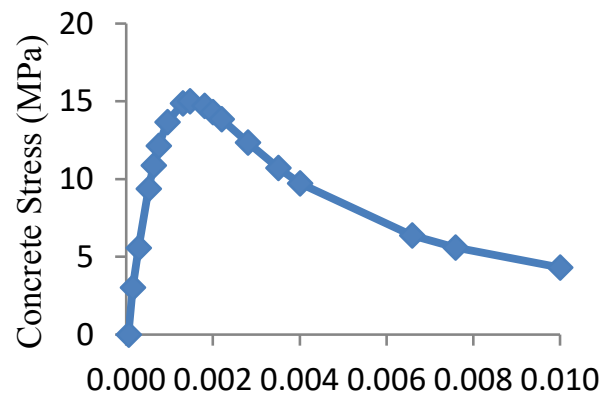

Concrete Strain

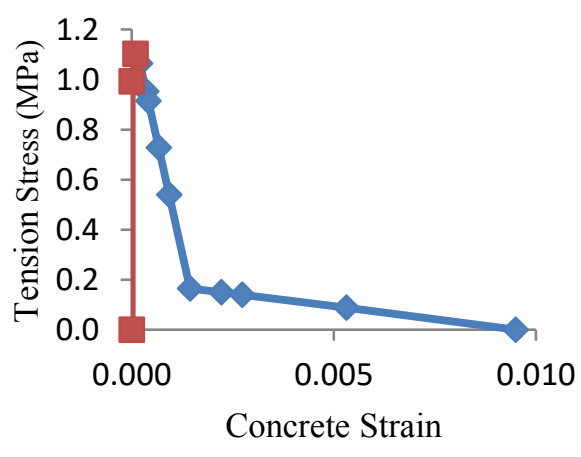

(b) Tension

(a) Compression

Fig. 3. Concrete stress-strain curve

The response of concrete for cyclic loading is decrease in elastic stiffness. Elastic stiffeness is an important aspect which is illustrated in Figure 4. ABAQUS uses value factors recovery of stiffness defined as $\mathrm{wt}=0$ and $\mathrm{wc}=1$. Wc factor causes the material to regain the full stiffness with no damage. Meanwhile, the value 0 of wc showed no stiffness recovery. However, during the tension loading, stiffness stress was ignored. When the load is removed, 
the elastic modulus recovery into (1-dt) Eo [10]. Cracks caused material damage defined by $\mathrm{dt}$ and $\mathrm{dc}$, which is calculated by the following equation:

$$
\bar{\sigma}_{c}=\frac{\sigma_{c}}{\left(1-d_{c}\right)}=E_{0}\left(\varepsilon_{c}-\varepsilon_{c}^{p l}\right)
$$

Where $d_{c}$ is damage compression, $\bar{\sigma}_{c}$ is compressive stress in concrete corresponding to $f_{c}^{\prime}, \bar{\sigma}_{c}$ is compressive stress in concrete.

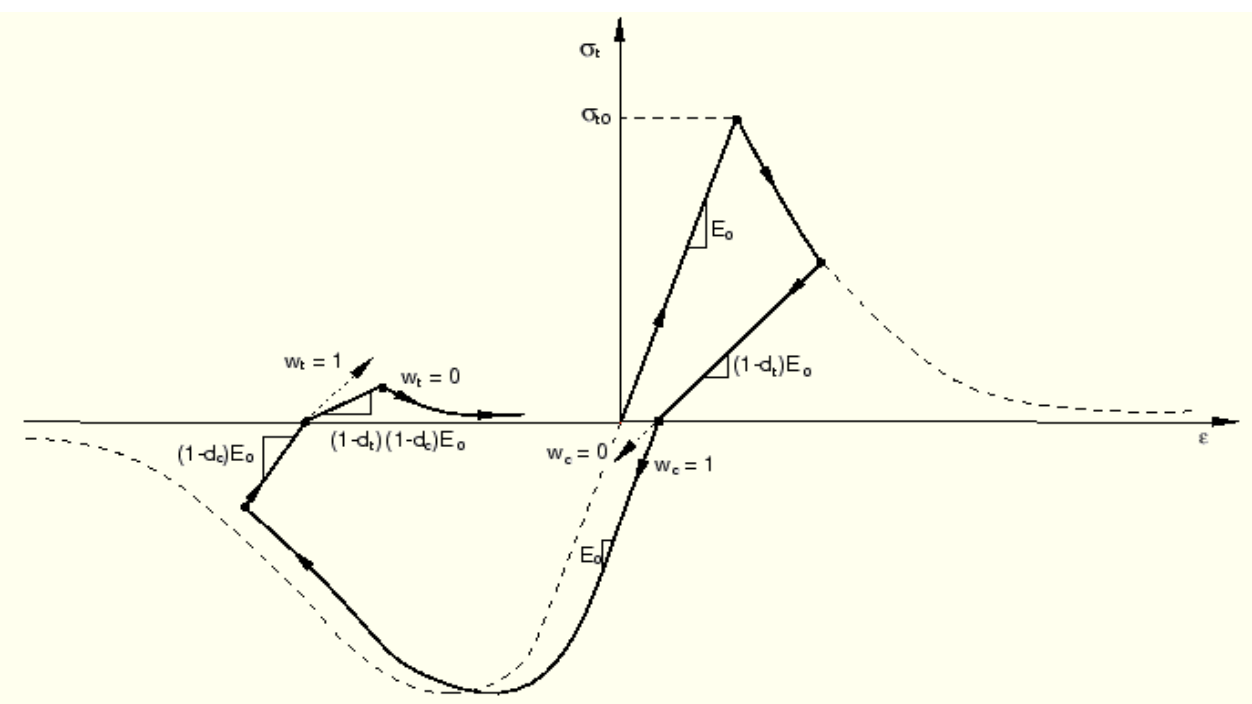

Fig. 4. Cyclic behavior of concrete [10]

In cracking conditions, the strain that occurs is called as the elastic strain $\varepsilon^{\text {in }}{ }_{c}$ and plastic strain $\varepsilon^{\mathrm{pl}}{ }_{\mathrm{c}}$. Inelastic strain can be defined as the total strain which is reduced by elastic strain on the material undamage conditions, with the following equation:

$$
\varepsilon_{\mathrm{c}}^{\mathrm{in}}=\varepsilon_{\mathrm{c}}-\varepsilon^{\mathrm{el}}{ }_{0 \mathrm{c}}
$$

with,

$$
\varepsilon_{0 c}^{e l}=\frac{\sigma}{E_{o}}
$$

Where $\varepsilon^{\text {in }}{ }_{\mathrm{c}}$ is inelastic strain, $\varepsilon_{\mathrm{c}}$ is strain in concrete, and $\varepsilon_{0 c}^{e l}$ is elastic strain.

\subsubsection{Steel material}

The steel reinforcing bars is modeled using a nonlinear isotropic or kinematic hardening. The development of this model consists of two components, namely component that describes the nonlinear kinematic hardening of translation in the yield area between the stress through backstress $(\alpha)$ and component hardening describing isotropic equivalent stress change is defined as the change in the form of plastic in the yield area [10]. 
The steel material was modelled from the material properties that have been tested by experiment. The material properties are used for the steel rebar, bolt, and steel plate shown in Table 1.

Table 1. Material properties of specimens

\begin{tabular}{|c|c|c|c|}
\hline $\mathrm{f}_{\mathrm{y}, \text { main }}(\mathrm{MPa})$ & $\mathrm{f}_{\mathrm{y}, \text { trans }}(\mathrm{MPa})$ & $\mathrm{f}_{\mathrm{y}, \text { bolt }}(\mathrm{MPa})$ & $\mathrm{f}_{\mathrm{y}, \text { steel plate }}(\mathrm{MPa})$ \\
\hline 545.803 & 688.816 & 493.073 & 452.476 \\
\hline
\end{tabular}

\subsection{Meshing, loading and boundary conditions}

In this study, beams and columns were meshing with a size of $30 \mathrm{~mm}$ for beam-column, 2 $\mathrm{mm}$ steel, $1 \mathrm{~mm}$ bolts and $2 \mathrm{~mm}$ steel plate, for resulting in a stable number of elements. The boundary conditions are set at each end of the beam as hinge. This numerical model using two types of load, axial load of $33.75 \mathrm{kN}$ was applied at the top of the column as a uniform pressure and displacement control given at the bottom of column. The cyclic loading was applied accordance by ACI T1.1-01 [11].

\section{Results and discussion}

The FE analysis conducted to investigate envelope of the hysteresis load-displacement response, crack pattern, ductility, and energy dissipation in the specimens. The analysis result report are discussed in this section.

\subsection{Specimen HBK-1NA}

Specimen HBK-1NA is a normal beam-column used as control test specimen against the test specimen HBK-3A. HBK-1NA generated load at peak condition at the positive and negative cycle that is equal to $8.44 \mathrm{kN}$ and $16.31 \mathrm{kN}$. HBK-1NA stiffness cycle on twelfth cycle to the positive and negative direction were $20.3 \%$ and $65.2 \%$. Pattern of collapse on the test specimen HBK-1NA formed as fine cracks that occur at a drift of $3(0.27 \%)$ that is at the interface of the beam-column joint. At drift of 14 (3.75\%), yielding in the steel reaching stress about $547.4 \mathrm{MPa}$ and strain equal to 0.0924 . Cracks that were occurred on HBK-1NA were dominated by shear cracks in the inside of the beam-column joint. From the pattern of collapse that occurred, it can be concluded that the HBK-1NA has not qualified as strong column weak beam mechanism.

\subsection{Specimen HBK-3A}

Specimens HBK-3A is a beam-column with the longitudinal reinforcement at the joint does not reach $400 \mathrm{~mm}$ which strengthened with steel strip plates given at joint of interior beamcolumn. HBK-3A generated load at peak condition of $10.16 \mathrm{kN}$ on a positive cycle and 15.99 $\mathrm{kN}$ on the negative cycle. Stiffness cycle HBK-3A in the twelfth step to the positive and negative direction were $9.4 \%$ and $47.8 \%$. Pattern of collapse on the test specimen HBK-3A formed as initial cracks that occur at a drift of $2(0.36 \%)$, that crack in the parts of columns. At drift of $14(3.76 \%)$ yielding in the steel reaching stress about $542.1 \mathrm{MPa}$ at the connection steel strip plate and bolt. Further cracks that occur in the HBK-3A is dominated by shear cracks in the concrete columns and steel strip plate section that began buckling shown in Figure 5. The specimen HBK-3A showed that strengtening using steel plates can increase the shear capacity on beam-column joint, shear cracks at the joint moved to the column which 
was caused by stress concentration that occurred at the connection between the steel plates and bolts.

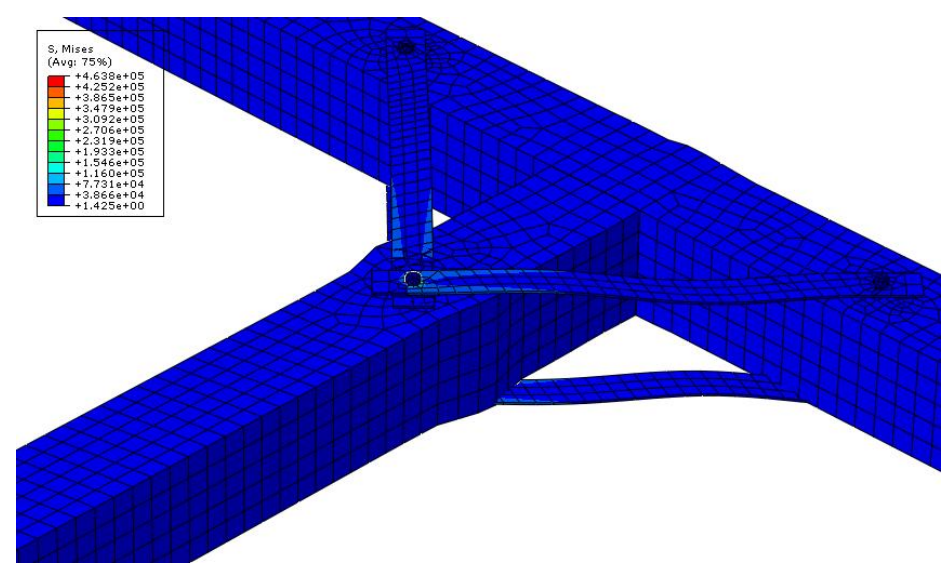

Fig. 5. Stress of HBK-3A

\subsection{Ductility}

Ductility is the ability of a structure and selected structural components to deform beyond elastic limits without excessive strength or stiffeness degradation [12]. Specimen HBK-3 in the positive and negative direction, have a greater ductility $15.38 \%$ and $37.78 \%$ compared than HBK-1NA. The value of ductility factor result proves that the beam-column joint strenghthened using steel plate (HBK-3A) has a greater ductility in positive and negative cycles.

\subsection{Strength degradation}

The peak load with displacement on each drift ratio for initial cycle loading shown in Figure 6 . Figure 6 shows that in the positive direction, HBK-3A has increased by $0.17 \%$ against HBK-1NA. In the negative direction, HBK-3A has a lower lateral load of $0.02 \%$ than HBK1NA. From the results of the three envelope curves shows the HBK-3A generated load and displacement with high average in the positive and negative direction. However, on the negative cycle is lower due to concrete cracking in the connection area. 


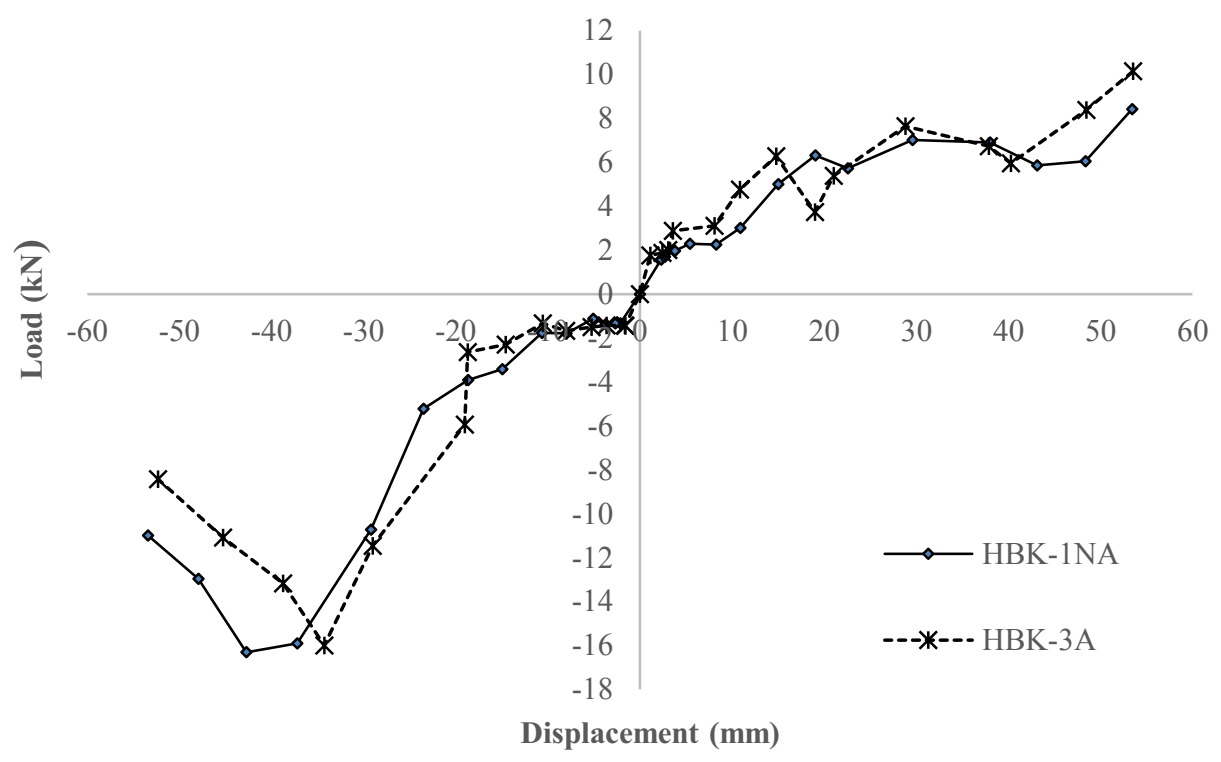

Fig. 6. Comparison of load-displacement of each specimen

\subsection{Energy dissipation}

The energy dissipation structure describes the ability of the structure to absorb energy due to external loads. The relative energy dissipation ratio $(\beta)$ is the ratio between the energy dissipated by the actual structure by theoretical calculations. Energy dissipation relative value ( $\beta$ ) should not be less than 1/8. Energy dissipation relative to all specimens shown in Table 2 .

Table 2. Dissipation energy for all specimens

\begin{tabular}{|c|c|c|c|}
\hline Specimens & Drift ratio $(\%)$ & $\mathrm{Ah}(\mathrm{kN} \mathrm{mm})$ & Energy dissipation relative $(\beta)$ \\
\hline HBK-1NA & $3.75 \%$ & 59.13 & 0.09 \\
\hline HBK-3A & $3.76 \%$ & 192 & 0.186 \\
\hline
\end{tabular}

Table 2 shows that the dissipation of energy generated on HBK-1NA was not qualified of the limit values required by ACI TI.1-01 is 0.125 . Specimen HBK-3A was qualified in accordance the criteria specified.

\subsection{Comparison of experimental and numerical results}

The results of numerical analysis in this study compared to experimental results by Pranadita (2016) to observe the validation of the data obtained from the results of a numerical approach. The load and displacement in peak condition resulting in numerical analysis compared with the experimental results are shown the load generated in the specimen HBK-1NA and HBK$3 \mathrm{~A}$ have differences with the experimental results on the positive and negative cycles. On the positive cycle, HBK-1NA have difference about $11.99 \%$ than HBK-1NE and HBK-3A about $9.52 \%$ than HBK-3E. It is effected by different of patterns of collapse in the positive and negative cycles, primarily because of the following:

a. Reinforcement on modeling, is considered as a perfect bond with an embedded. 
b. The equation on the material properties that are used need to be investigated in order to obtain almost the good results.

\subsubsection{Specimens HBK-1NA}

The pattern of cracks that occur in the numerical analysis of the test specimen HBK-1NA until the end of the cycle was formed of shear cracks on the joint in the beam-column, crack pattern is similar to the cracking that occurred in the HBK-1NE. The crack of initiation in the numerical results occurred in the third step with a strain of 0.0013 , whereas in the experimental initial crack occurred on the sixth step. Comparison of the pattern of cracks that occur on HBK-1NA and HBK-1NE shown in Figure 7 below.

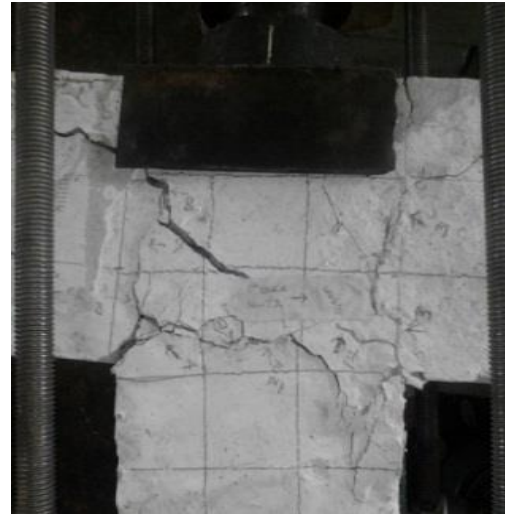

(a) HBK-1NE

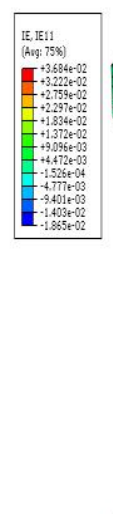

Fig. 7. Comparison of the cracks pattern on HBK-1NE and HBK-1NA

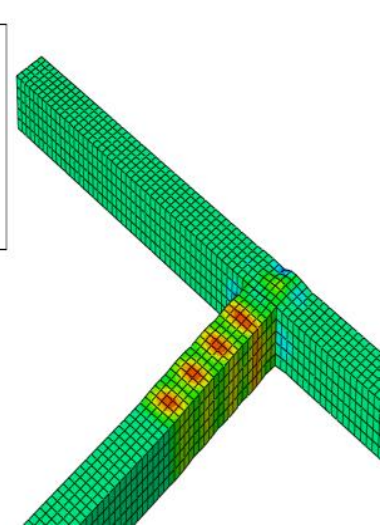

(b) HBK-1NA

\subsubsection{Specimens HBK-3A}

The pattern of initial crack at HBK-3A was occurred at the second step, while at the HBK$2 \mathrm{E}$ was occurred in the fourth step. HBK-3A cracks at the last cycle were in the form of cracks on the concrete in the columns as shown in Figure 8. On HBK-3E, cracks that were occurred in the form of concrete on the columns experienced which was large and deep, until the main reinforcing steel was exposed (Pranadita, 2016).

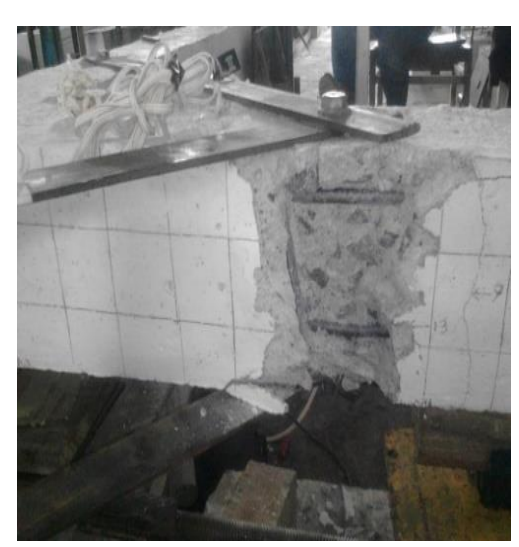

(a) HBK-3E

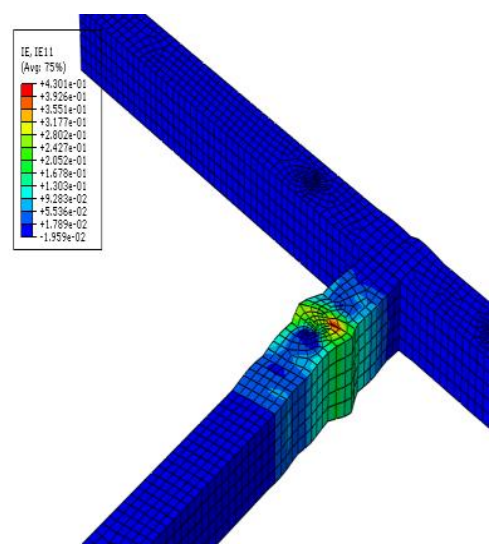

(b) HBK-3A

Fig. 8. Comparison of the cracks pattern on HBK- $3 E$ and HBK-3A 


\section{Conclusion}

The nonlinear material model predicted the behavior of beam-column joint well. Although some differences have been seen amongst the result, but the shear cracks on the joint in the numerical model has good agreement with the experimental results. Based on modeling results, discussion, and analysis of data that has been presented, some conclusions can be obtained as follows:

1. The test specimen HBK-3A generated maximum lateral load in the negative direction and the positive direction to $10.16 \mathrm{kN}$ and $15.99 \mathrm{kN}$, whereas on HBK-3E to $11.23 \mathrm{kN}$ and $11.58 \mathrm{kN}$. The resulting differences in numerical results were $9.52 \%$ and $38.08 \%$ against the experimental results.

2. From the pattern of collapse that occur, HBK-3A can increase the capacity of shear on the join. Crack only occurred in the area of steel plate connection on the column.

3. The relative energy dissipation $(\beta)$ in the test specimen HBK-1NA and HBK-3A were 0.09 and 0.186 . Specimens strengthened using steel plate (HBK-3A) in accordance the criteria required by ACI TI.1-01.

4. In this research, the specimen HBK-1NA and HBK-3A have not qualified as "strong column weak beam" from the mechanism of collapse pattern.

5. The use of steel strip plate on the beam-column connection in non-engineered buildings was more effective, because it did not require a long time and it was an easy installation process.

\section{References}

1. T. Boen, Earthquake Resistant Design of Non-Engineered Buildings In Indonesia (2001)

2. G. H. Pranadita, Analisis Perilaku Hubungan Balok-Kolom Interior Pada Struktur Beton Bertulang Non-Engineered Dengan Perkuatan Plat Baja (Universitas Gadjah Mada, 2016)

3. D.G. Weng, C. Zhang, J.D. Xia, and X.L. Lu, 15 W. C. E. E. (2012)

4. A. Sharma, R. Eligehausen, and J. Hofmann, ACI Struc. J., 111, 4 (2014)

5. M. K. Sharbatdar, A. Kheyroddin, and E. Emami, J. Els. Const. Build. Mat., 36, 287-294 (2012)

6. D. A. Pohoryles, J. Melo, and T. Rosetto, Earth. R. Eng. Res. W. (2015)

7. P. Kmiecik and M. Kaminski, Arc. Civ. Mech. Eng., XI, 3 (2011)

8. F. Oudah, Development of Innovative Self-Centering Concrete Beam-Column Connections Reinforced using Shape Memory Alloys (Department of Civil Engineering University of Calgary, 2014)

9. T. Telford, CEB-FIP Model Code 1990 Design Code, (Comite Euro-Du International Betong, 1991)

10. ABAQUS User Manual, ABAQUS (2006)

11. ACI, Acceptance Criteria for Momen Frames Based on Structural Testing T1.1-01, (American Concrete Institute, 2001)

12. T. Paulay, T. and Priestley, M. J. N, Seismic Design of Reinforced Concrete and Masonry Buildings (Wiley and Sons, 1992) 